\title{
A Population-Based Study of the Association of Medical Manpower with County Trauma Death Rates in the United States
}

Robert Rutledge, M.D., Samir M. Fakhry, M.D., Christopher C. Baker, M.D., Nancy Weaver, B.S., Max Ramenofsky, M.D., George F. Sheldon, M.D., and Anthony A. Meyer, M.D., Ph.D.

From the Department of Surgery, University of North Carolina School of Medicine, Chapel Hill, North Carolina

\section{Objective}

To determine the association between measures of medical manpower available to treat trauma patients and county trauma death rates in the United States. The primary hypothesis was that greater availability of medical manpower to treat trauma injury would be associated with lower trauma death rates.

\section{Summary Background Data}

When viewed from the standpoint of the number of productive years of life lost, trauma has a greater effect on health care and lost productivity in the United States than any disease. Allocation of health care manpower to treat injuries seems logical, but studies have not been done to determine its efficacy. The effect of medical manpower and hospital resource allocation on the outcome of injury in the United States has not been fully explored or adequately evaluated.

\section{Methods}

Data on trauma deaths in the United States were obtained from the National Center for Health Statistics. Data on the number of surgeons and emergency medicine physicians were obtained from the American Hospital Association and the American Medical Association. Data on physicians who have participated in the American College of Surgeons (ACS) Advanced Trauma Life Support Course (ATLS) were obtained from the ACS. Membership information for the American Association for Surgery of Trauma (AAST) was obtained from that organization. Demographic data were obtained from the United States Census Bureau. Multivariate stepwise linear regression and cluster analysis were used to model the county trauma death rates in the United States. The Statistical Analysis System (Cary, NC) for statistical analysis was used.

\section{Results}

Bivariate and multivariate analyses showed that a variety of medical manpower measures and demographic factors were associated with county trauma death rates in the United States. As in other studies, measures of low population density and high levels of poverty were found to be strongly associated with increased trauma death rates. After accounting for these variables, using multivariate analysis and cluster analysis, an increase in the following medical manpower 
measures were associated with decreased county trauma death rates: number of board-certified general surgeons, number of board-certified emergency medicine physicians, number of AAST members, and number of ATLS-trained physicians.

\section{Conclusions}

This study confirms previous work that showed a strong relation among measures of poverty, rural setting, and increased county trauma death rates. It also found that counties with more board-certified surgeons per capita and with more surgeons with an increased interest (AAST membership) or increased training (ATLS) in trauma care have lower per-capita trauma death rates. These findings are consistent with the hypothesis that physicians with increased interest and training in trauma care decrease the devastating toll of injury in the United States.

Trauma is devastating in the United States. An estimated 58 million persons were injured in 1989, yielding an overall rate of 223 injured persons per 1,000 population. ${ }^{1}$ Each year, trauma accounts for 140,000 deaths, with three disabling injuries for each death. The yearly total costs of injury ${ }^{1}$ are $\$ 177.2$ billion. In addition, hospitalization charges for injury are substantially greater than the average charges for hospital admission $(\$ 12,000$ compared with $\$ 5,000$ ). A variety of interventions have been suggested as possible means to lessen the effect of injury in the United States. ${ }^{2}$ These approaches include prevention programs, the development of trauma centers and regionalized trauma systems, and support for physician manpower committed to trauma care. Unfortunately few data exist that allow health care professionals to determine the relative value of these interventions.

Increased skill in recognizing and managing injuries should lead to better outcomes for injured patients based on a decrease in errors in management and a decrease in preventable deaths that occur. ${ }^{3}$ Health manpower resources must be available to manage the acute care of the injured patient. Conversely, the absence of adequately trained health care professionals might be associated with worse outcomes after injury. Although it would seem reasonable to assume that the characteristics and level of training of the health care team would affect the outcome of injury (that is the availability of more and better trained physicians to treat injured patients might improve survival rates and decrease complications), in today's changing health care system we must prove the benefits of the use of costly health care resources. If substantial benefit can be realized, further study of more effective distribution of manpower resources can begin.

Presented at the 105th Annual Scientific Session of the Southern Surgical Association, December 5-8, 1993.

Address reprint requests to Robert Rutledge, M.D., Department of Surgery, University of North Carolina School of Medicine, CB 7210 Burnett-Womack Building, Chapel Hill, NC 27599-7210.

Accepted for publication December 7, 1993.
Unfortunately few data describe or analyze the distribution of medical manpower available to treat injured patients in the United States. Thus the optimal location and distribution of manpower for the treatment of injury is unknown.

Given the absence of definitive proof of the effect of allocating manpower resources to treat injured patients, the purpose of this study was to assess the association between several measures of medical manpower and county death rates in the United States. Conclusions of this study must be tempered by the limitations of available data sources. However such a study might be useful in developing a methodology to address these questions and describing and quantifying the necessary resources required for optimal care of injured patients.

\section{METHODS}

\section{Study Plan}

Our primary hypothesis for this study was that the availability of properly trained physician manpower would be associated with improved outcome after injury. The independent variables in the analyses were a variety of measures of medical manpower, including the numbers of physicians, surgeons, emergency medicine physicians, Advanced Trauma Life Support (ATLS)-trained physicians, and American Association for Surgery of Trauma (AAST) members. The dependent variable was the per-capita trauma death rate in the counties of the United States. We tried to develop a linear model that would predict the change in the county trauma death rate using the candidate independent variables. Many problems are associated with such a modeling procedure, and many of them are addressed below. Many other factors besides medical manpower were shown to be associated with the outcome of injury (poverty, race, and rurality for example), and the analysis plan was designed to account for these factors. 


\section{Dependent Variable}

The analyses in this study were based on a dependent variable that described the outcome of injury as county trauma death rate. Although many injury outcome measures can be imagined, the data available on outcome after injury on a national scale are severely limited because there is no well-validated national data source on injury. This lack of a national information source on injury and its outcomes lead to the development of the Trauma Registry of the American College of Surgeons. The National Center for Health Statistics maintains a limited nationwide data base of all deaths, including deaths from injury, that occur in the United States each year. Data are obtained from death certificates, which contain limited information, and thus the quality of this data is inconsistent. Despite its limitations, this data source has been used by others to gain some knowledge of trauma in the United States. ${ }^{4}$

The dependent variable used in this study was the number of trauma deaths (excluding poisoning and drowning) that occurred in each county in the United States during 1988, the last year for which data were available for this study. Because of the different sizes and populations of counties, a per-capita county trauma death rate was calculated for each county (number of trauma deaths divided by the population of the county). The per-capita county trauma death rates from the 3,080 counties in the United States were analyzed using counties as the unit of analysis for the following reasons: (1) comparability, because many of the available data sources group information by county; (2) localization of the effect because we expected that the effect of a physician would be felt geographically at the county level; and (3) zip code areas seemed too small and states too large for an effect to be measured.

\section{Independent Variables}

As described above, several other factors are associated with county trauma death rates besides the physician resources in the county. These other covariables were identified and controlled for as much as possible. Several studies identified the association of demographic factors such as the rural/urban mixture of the county, racial composition, and poverty with trauma death rates. To control for these factors, these covariables were analyzed as part of a multivariate model.

There were two groups of independent variables studied in this analysis. The first group included the measures of medical manpower, and the second included the nonmanpower measures identified as possible important co- variables in the study, including demographic factors and other medical system factors, as depicted in Table 1 .

\section{Measures of Medical Manpower}

Several measures of county physician resources and training in the United States were available for analysis, but they were limited because they did not identify the amount of physician time committed to or level of expertise in trauma care. However they did represent numbers of physicians trained in specialties that included trauma as a required part of the curriculum, and academic and professional interests in trauma care. The measures included the number of all types of physicians in each county, the number of board-certified general surgeons in each county, the number of emergency medicine physicians in each county, the number and type of ATLS students from a sample of all ATLS students, and the membership list of the AAST.

\section{Demographic Factors}

Although our primary interest in this study was determining the association between measures of medical manpower and trauma deaths, the importance of other factors could not be ignored because they have a strong association with trauma death rates. Studies by Baker, ${ }^{4}$ our group, ${ }^{5-9}$ and others showed a strong association between a constellation of demographic factors and county per-capita trauma death rates. Therefore we quantified and controlled for these other factors in the modeling process that are associated with changes in trauma death rates. Attention to the effects of these covariables is necessary because simple bivariate analysis may be misleading; therefore we included the demographic factors that have been shown to be associated with trauma death rates in the analysis. ${ }^{5-9}$ These include factors such as measures of rurality and population density and measures of income and job status. Data were available on the population, the population density, the mean personal income, and the unemployment rates in all United States counties in 1988. We obtained demographic data from the United States Census Bureau and the University of North Carolina Department of Surgery demographic data base. We included these factors in the bivariate analyses and as part of the multivariate modeling procedure to control for differences in counties in the analyses. The demographic variables previously shown to be associated with trauma death rates are listed in Table 1 .

\section{Data Sources}

The description of sources, the values, and the limitations of each data point are listed below for physicians 
Table 1. DEMOGRAPHIC VARIABLES ASSOCIATED WITH TRAUMA DEATH RATES

\begin{tabular}{|c|c|c|c|c|c|}
\hline Variable & Mean & SD & Sum & Minimum & Maximum \\
\hline All deaths & 683.56 & 2166.35 & $2,105,361$ & 0 & 62,940 \\
\hline Total trauma deaths & 35.32 & 100.9 & 108,796 & 0 & 3210 \\
\hline All deaths $/ 10,000$ population & 98.17 & 26.84 & 302,375 & 0 & 222.22 \\
\hline Trauma deaths $/ 10,000$ population & 5.77 & 3.07 & 17,781 & 0 & 40 \\
\hline County population & 79,806 & 261,703 & $245,802,900$ & 100 & $8,587,800$ \\
\hline Population density & 208.73 & 1645.94 & 642,897 & 0.15 & 68,632 \\
\hline Log population density & 3.64 & 1.6 & 11,218 & -1.9 & 11.14 \\
\hline Mean personal income & 12,543 & 2999.36 & $38,632,935$ & 0 & 37,844 \\
\hline \% Unemployment & 6.75 & 3.33 & 20,794 & 0 & 33.5 \\
\hline$\%$ Black & 8.56 & 14.39 & 26,353 & 0 & 84.2 \\
\hline No. of hospitals/county & 1.84 & 3.89 & 5681 & 0 & 135 \\
\hline County hospital & 0.83 & 0.38 & 2544 & 0 & 1 \\
\hline No. of physicians & 147.96 & 677.78 & 455,729 & 0 & 20,359 \\
\hline No. of physicians $/ 10,000$ population & 8.76 & 8.97 & 26,971 & 0 & 192.73 \\
\hline No. of ED physicians & 2.76 & 11.36 & 8496 & 0 & 329 \\
\hline \multicolumn{6}{|l|}{ No. of ED physicians $/ 10,000$} \\
\hline population & 151.73 & 465.66 & 467,319 & 0 & 17,895 \\
\hline No. general surgeons on hospital staff & 12.56 & 55.1 & 38,685 & 0 & 1564 \\
\hline No. Staff surgeons $/ 10,000$ population & 0.89 & 1.05 & 2749.3 & 0 & 14.29 \\
\hline No. of board-certified general surgeons & 9.81 & 43.62 & 30,227 & 0 & 1186 \\
\hline \multicolumn{6}{|l|}{ No. of board-certified general } \\
\hline surgeons/10,000 population & 0.63 & 0.82 & 1932.65 & 0 & 9.52 \\
\hline No. of all ATLS students & 9.89 & 41.79 & 30,461 & 0 & 938 \\
\hline \multicolumn{6}{|l|}{ No. of all ATLS students $/ 10,000$} \\
\hline population & 7.71 & 16.64 & 23,751 & 0 & 606.06 \\
\hline No. of ATLS general surgeons & 0.92 & 4.07 & 2828 & 0 & 86 \\
\hline \multicolumn{6}{|l|}{ No. of ATLS general surgeons $/ 10,000$} \\
\hline population & 0.7 & 2.26 & 2163.59 & 0 & 41.67 \\
\hline No. of ATLS ED MDs & 1.6 & 5.46 & 4927 & 0 & 123 \\
\hline \multicolumn{6}{|l|}{ No. of ATLS ED MDs $/ 10,000$} \\
\hline population & 1.25 & 2.81 & 3838.34 & 0 & 36.23 \\
\hline No. of AAST members & 0.15 & 1.03 & 457 & 0 & 21 \\
\hline \multicolumn{6}{|l|}{ No. of AAST members $/ 10,000$} \\
\hline population & 0.38 & 3.39 & 1181.83 & 0 & 121.21 \\
\hline AAST member in county & 0.04 & 0.21 & 136 & 0 & 1 \\
\hline
\end{tabular}

and surgeons, ATLS students, and members of the AAST.

\section{Physicians and Surgeons}

Data on the locations, numbers, and specialties of physicians in the United States were obtained from the American Medical Association.

\section{Advanced Trauma Life Support Students}

The American College of Surgeons (ACS) has been training providers in the ATLS course since 1980, and more than 150,000 students have completed the course. In 1985 the ACS created a data base of the students trained in ATLS including their location and specialty. This was the data source for the ATLS-trained persons in each county for this study. Although the data base is incomplete, we thought it would be reliable as a sample of all ATLS-trained physicians. We obtained independent variables from the ATLS data base by calculating the number of students, general surgeons, and emergency physicians in each county who had completed the course. We calculated a per-capita rate for these values for each county by dividing the number of ATLS participants by the population and multiplying this number by 100,000 . We used each of these variables as candidate variables for the analysis.

\section{American Association for the Surgery of Trauma Members}

The AAST is an academic professional organization of surgeons who are committed to trauma care. Membership requirements include demonstrated clinical and organizational involvement in trauma care and research. General surgeons account for most members, but many 


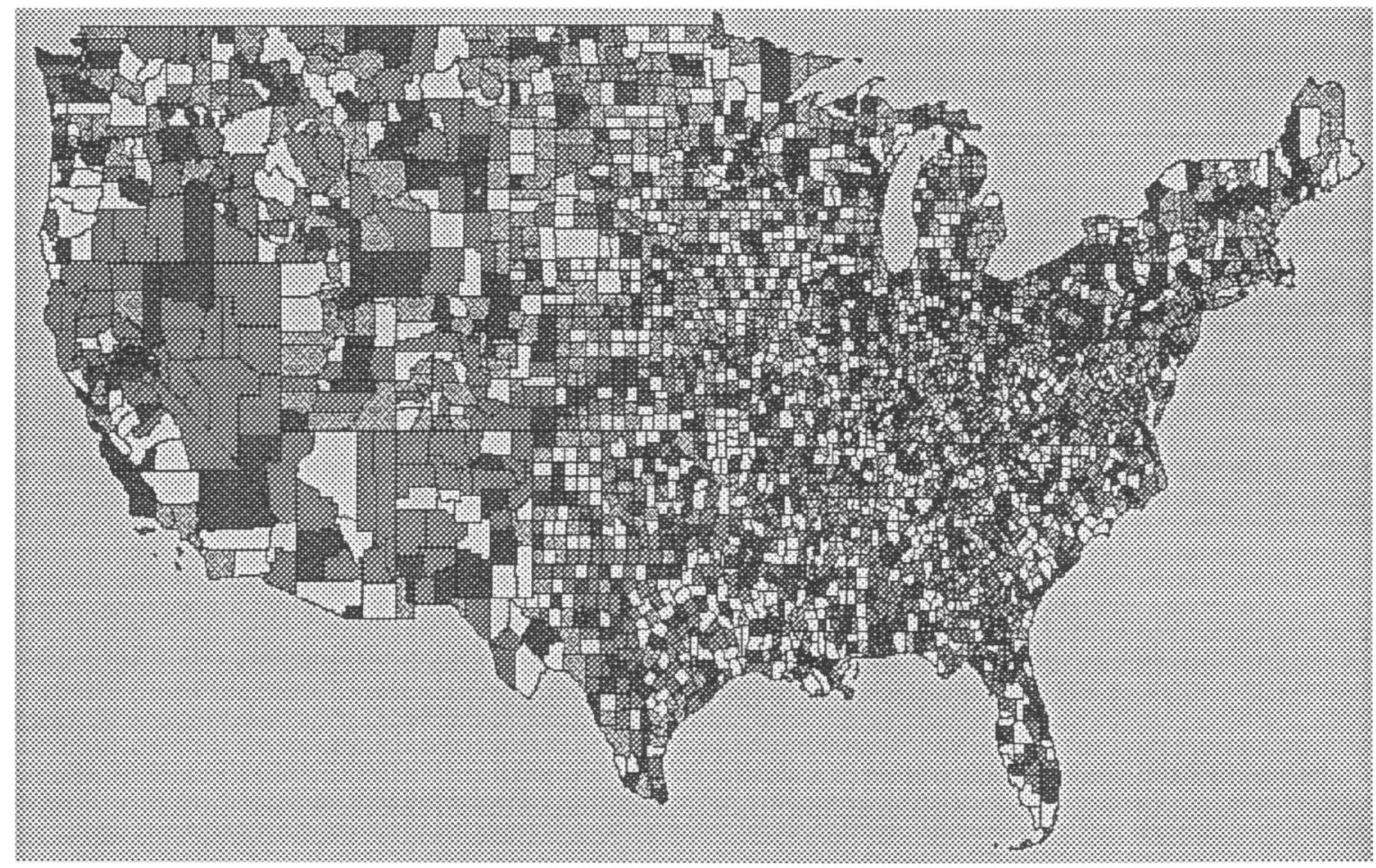

Figure 1. Distrubution of trauma deaths in the United States.

orthopedic surgeons, neurosurgeons, plastic surgeons, and other surgical specialists are members. We used the professional addresses provided by the secretary-treasurer's office to determine their county of practice.

\section{Statistical Analysis}

Univariate and bivariate analyses were performed to describe the distribution of the candidate variables for the study. Correlation analyses were performed to determine the association between the independent variables

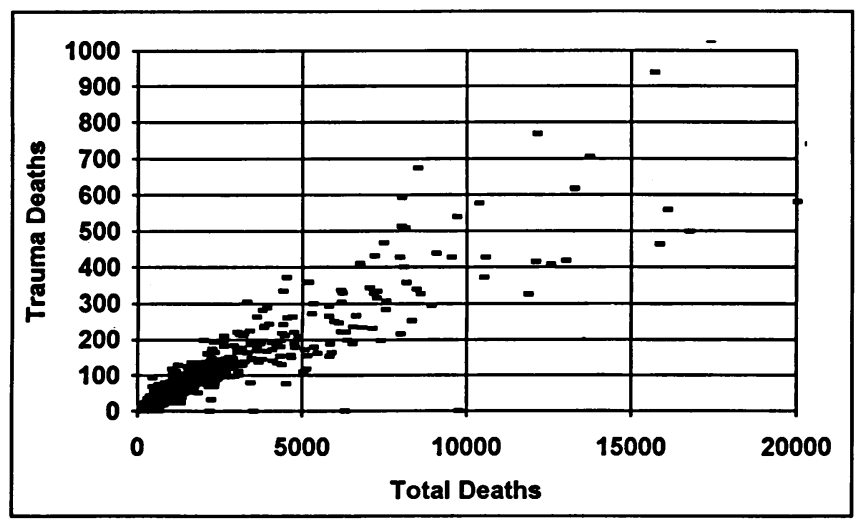

Figure 2. Association of total deaths and trauma deaths. and the per-capita county trauma death rates and to identify internal correlations among candidate variables that would have an effect on the multiple regression analyses. We selected those variables that were identified by bivariate methods as having strong predictive power for further testing using multivariate analysis. We used stepwise and backward selection analyses to create a model of trauma deaths in the counties.

Because of the potential effect of demographic factors on trauma deaths and the possibility that the effects described by the model might only be confounded, we re-

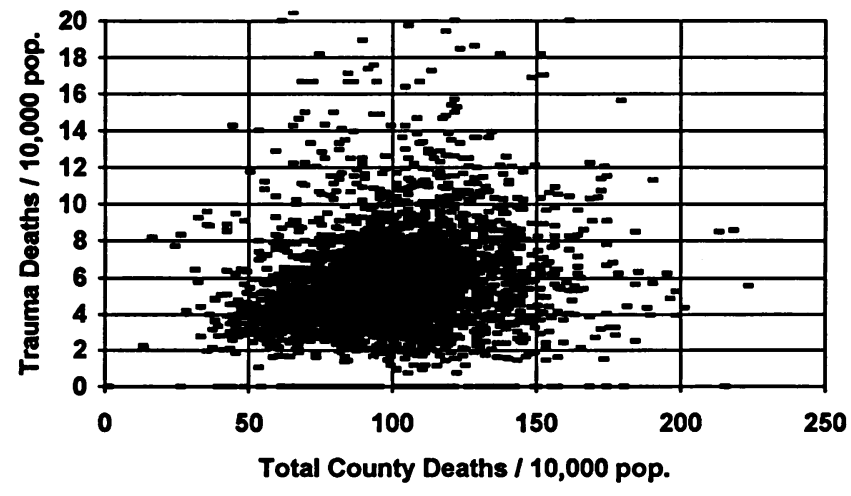

Figure 3. Association between total per-capita county deaths and county per-capita trauma deaths. 


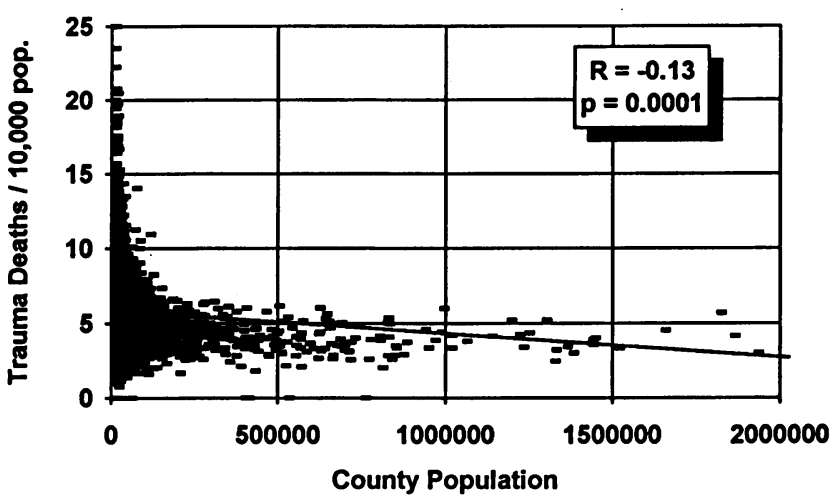

Figure 4. Association of population density and county per-capita trauma death rates.

peated regression analyses after forcing the best demographic predictors into the model. We used this approach to address the fact that counties with more medical manpower resources (such as surgeons or ATLS-trained surgeons) may have higher population densities (that is, the medical manpower factors might only be markers for other factors that are the true effectors changing county trauma death rates). Then we determined whether medical manpower factors are independently associated with trauma death rates.

To control further for the effect of demographic factors on outcome, we performed a cluster analysis (SAS PROC FASTCLUS; SAS, Cary, NC) to separate counties into four more homogenous groups using the demographic factors most strongly associated with trauma death rates. ${ }^{10-18}$ we repeated the multivariate regression analyses on each separate cluster of counties. Bivariate analyses showed that the log of the population density, the mean personal income, and the percentage of the county population that was black were the strongest demographic factors associated with trauma death rates.

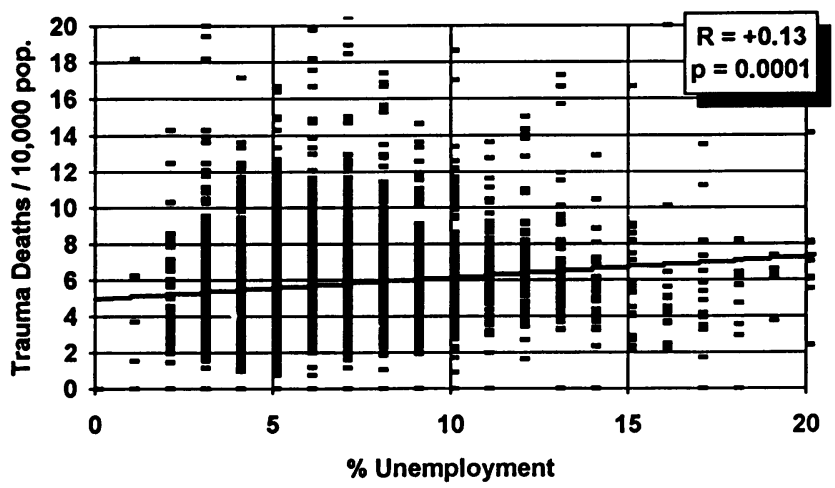

Figure 5. Association of unemployment rate and county per-capita trauma death rates.

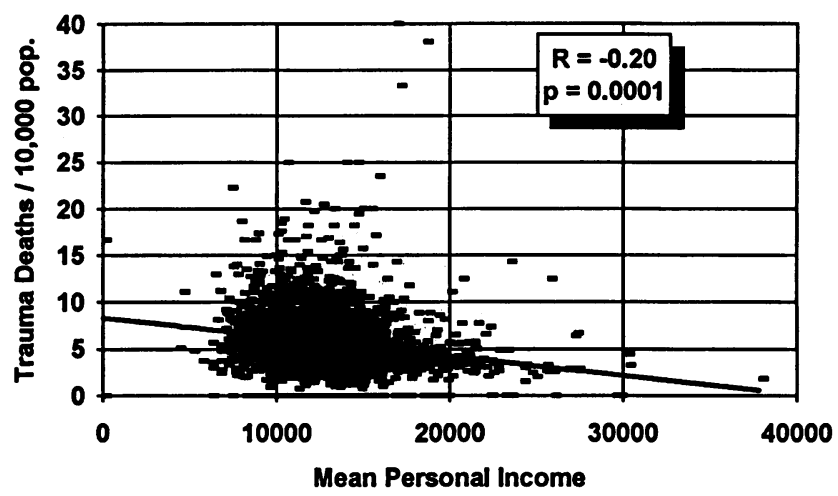

Figure 6. Association of personal income and county per-capita trauma death rates.

We used these factors in the cluster analysis to create four new groups of more homogeneous counties, and we used these subgroups in the subsequent multivariate analyses. We used the SAS PROC FASTCLUS procedure, which is designed to work with large data sets, to create disjoint clusters of the counties. We performed a disjoint cluster analysis on the basis of Euclidean distances computed from the three quantitative variables (the percentage of the county that was black, the mean personal income of the county, and the log of the population density of the county). We divided the counties into clusters such that every observation belonged to only one cluster.

We used the SAS system for statistical analysis for all statistical analyses. PROC FASTCLUS was created from direct inspiration from other work in cluster analysis. $^{10-18}$

\section{RESULTS}

Overall there were 2.1 million deaths available for analysis in the National Center for Health Statistics data

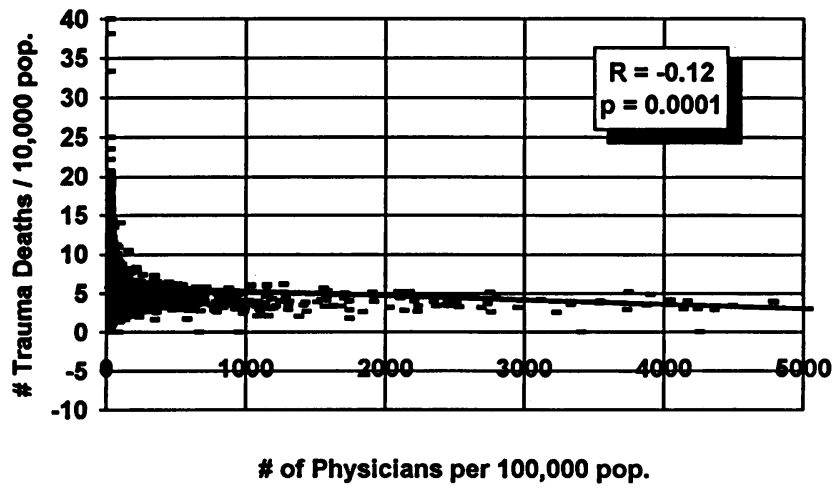

Figure 7. Association of number of physicians and county per-capita trauma death rates. 


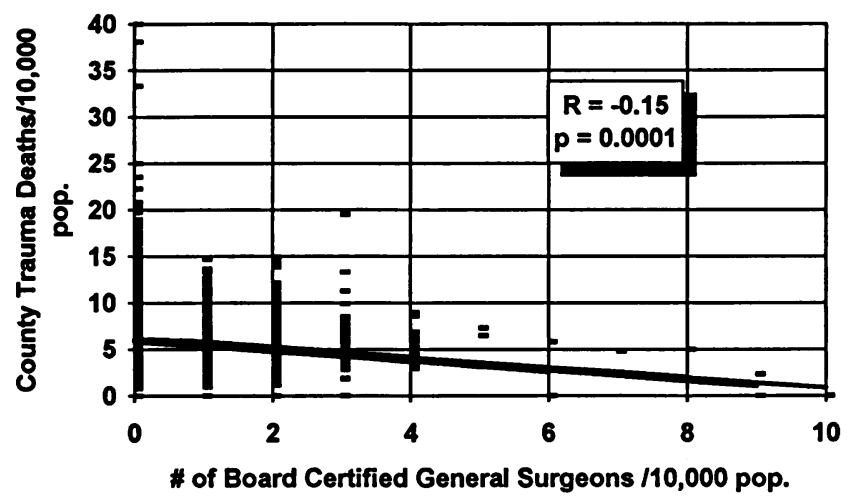

Figure 8. Association of number of general surgeons and county percapita trauma death rates.

base, with an average of 689 deaths per county (Fig. 1). Five percent, or 108,796 deaths, were related to injury. The per-capita total death rate was $98 \pm 27$ deaths per 10,000 population and the mean county trauma death rate was $5.77 \pm 3.07$ deaths per 10,000 population. A comparison of the total county trauma death rate to the county trauma death rate is shown in Figure 2. Comparisons of total per-capita trauma death rates and percapita trauma death rates are shown in Figure 3. Table 1 shows the distribution of the independent and dependent variables used in the study. For our study, the U.S. population at risk was $245,802,900$, with an average population of 79,806 $\pm 261,000$ per county, ranging from 100 to 8.6 million. Previous work by Baker ${ }^{4}$ showed a strong relation between county rurality (population density) and trauma death rates. In addition to population density, we calculated the log of population density because bivariate analyses has shown a better correlation between this derived variable and trauma death rates than raw population density. Other research found a re-

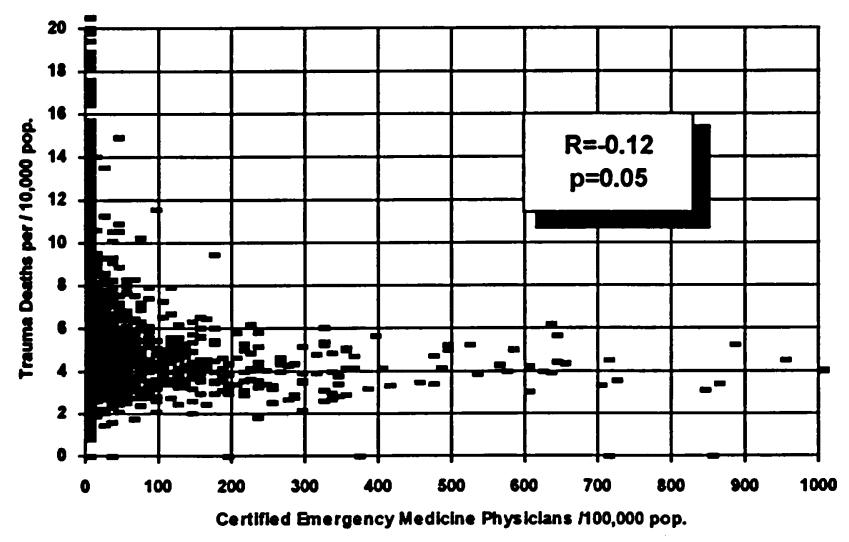

Figure 9. Association of number of emergency department physicians and county per-capita trauma death rates.

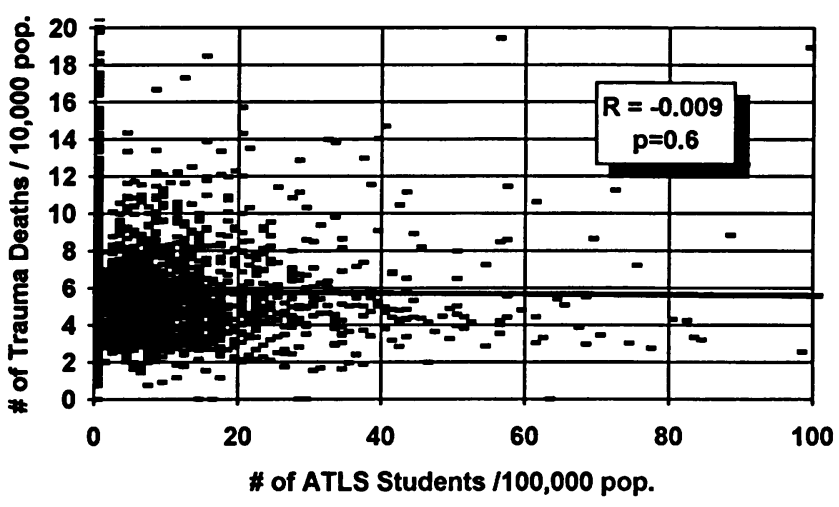

Figure 10. Association of number of ATLS students and county percapita trauma death rates.

lation between measures of poverty and trauma death rates. To control for these factors, we analyzed county mean personal income levels and county unemployment rates. The association between several of these demographic measures and per-capita trauma death rates are shown in Figures 4 through 6.

During this analysis, the United States had 5,681 acute care general hospitals, with an average of $1.84 \pm 3.89$ hospitals per county; $83 \%$ of counties had at least one hospital.

A variety of data was available on the medical manpower resources in each county, including data on the total numbers of hospitals, patient care physicians, emergency medicine physicians, and general surgeons. Each of these was standardized as rates for per-capita values. Demonstration of the association between some of these measures of medical manpower and per-capita trauma death rates are shown in Figures 7 through 14.

The total numbers of ATLS students, general surgeons, emergency physicians, and AAST members per county were also assessed. Again we used each of these values to determine per-capita values. The other details of the study population and the medical manpower resources are listed in Table 1.

\section{Bivariate Correlation Analyses}

Bivariate analyses of the association between the many independent variables and the covariables was completed by calculating Pearson's $R$ values within each cluster. The results are shown in Table 2 . All of the demographic factors studied were associated with total county death rates and per-capita county trauma death rates. It is also important to recognize that because of the large sample size, even relatively weak correlations were statistically significant. Of the demographic factors studied, the $\log$ of the population density and personal income were the strongest predictors of per-capita trauma 


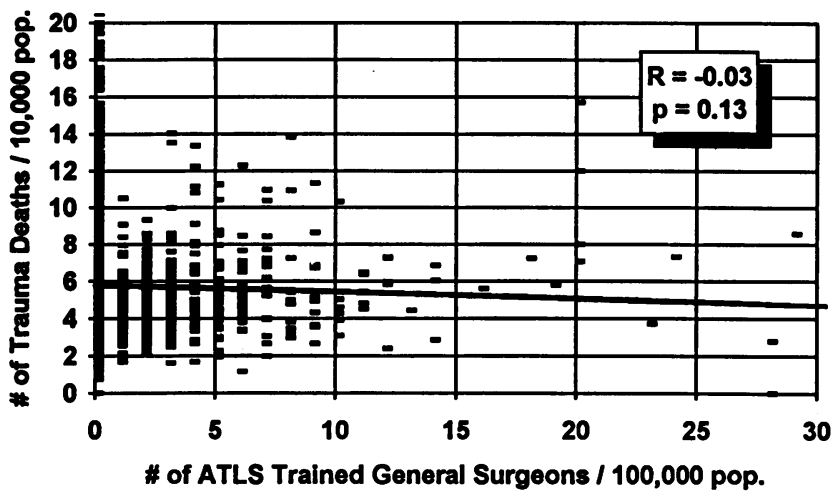

Figure 11. Association of number of ATLS-trained general surgeons and county per-capita trauma death rates.

death rates. The presence of a hospital and the number of hospitals in the county were both associated with lower trauma death rates. All of the measures of medical manpower were inversely related to per-capita trauma death rates.

Although this analysis shows an association of multiple variables with trauma death rates, this may be due to the considerable overlap among these variables (that is, they were covariables). Because the utility of bivariate analysis may be limited, multivariate regression analysis was used to study the relation between medical manpower resources and trauma death.

\section{Multivariate Analysis of the Entire Data Set}

The SAS linear regression procedures were used to create a model of trauma death rates in the U.S. counties. The results of the stepwise linear regression analysis are presented in Table 3. As shown, the first variables we selected for the model were the demographic factors that held the greatest predictive power (the log of the popula-

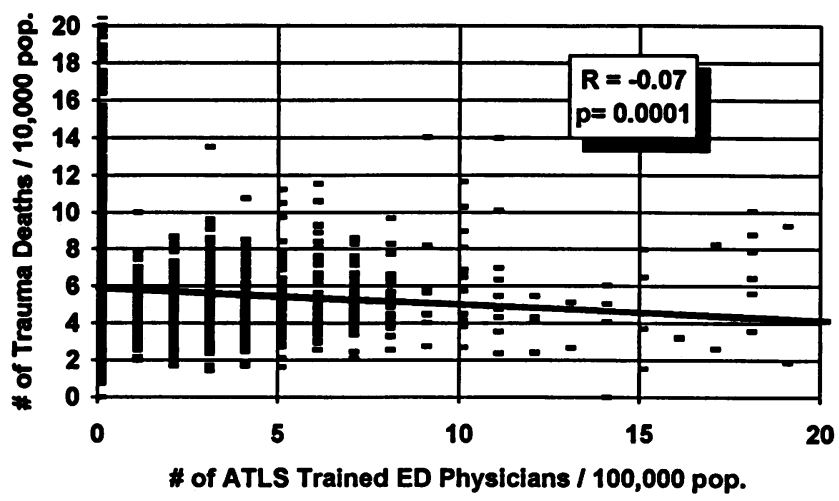

Figure 12. Association of number of ATLS-trained emergency department physicians and county per-capita trauma death rates.

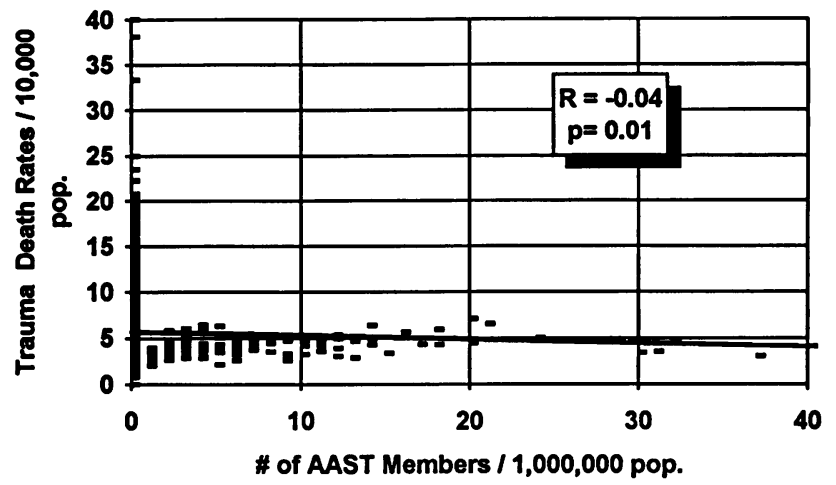

Figure 13. Association of number of AAST members and county percapita trauma death rates.

tion density, the mean personal income in the county, the unemployment rate, and the percentage of the population that was black). After these variables, six measures of medical resources were included (numbers of hospitals, physicians, surgeons, emergency medicine physicians, ATLS students, and AAST members). Although the regression modeling program had access to the absolute numbers of general surgeons, physicians, and emergency physicians, the best predictors were the per-capita measures of these resources. No measure of the number or presence of a hospital in a county contributed to the predictive power of the model.

Although the results of these analyses are interesting, the strong effect of the demographic factors is a concern, as is the low overall regression coefficient of 0.115 for the model. Therefore the next step in the plan of analysis was to use cluster analysis to create subgroups that were more homogeneous than the entire group.

\section{Cluster Analysis}

Preliminary analyses in this and other studies showed a strong association between several demographic factors and trauma death rates. ${ }^{3-7}$ To stratify the counties in America to allow better control of these demographic factors, we subjected counties to a cluster analysis to divide them into more homogeneous groups and to allow us to make clearer conclusions about the association of the measures of medical manpower with trauma death rates. Based on the bivariate analysis, we used three variables (percentage of unemployment, log of population density, and percentage of the county population that was black) to develop the clusters of counties for subsequent analyses. Tables 4 through 7 list the univariate simple statistics of the four county clusters.

\section{Cluster 1 (Average Rural)}

This group was made up of 1,555 counties that have lower population densities ( 56 vs. 208), lower percentage 
Table 2. CORRELATION ANALYSES

\begin{tabular}{|c|c|c|c|c|}
\hline & \multicolumn{2}{|c|}{$\begin{array}{c}\text { All Deaths } / 10,000 \\
\text { Population }\end{array}$} & \multirow{2}{*}{$\begin{array}{l}\text { Trauma Deaths } / 10,000 \\
\text { Population Pearson's R }\end{array}$} & \multirow[b]{2}{*}{ p Value } \\
\hline & Pearson's R & p Value & & \\
\hline County population & -0.1423 & 0.0001 & -0.13401 & 0.0001 \\
\hline Population density & -0.01562 & 0.3861 & -0.08072 & 0.0001 \\
\hline Log population density & -0.2329 & 0.0001 & -0.27595 & 0.0001 \\
\hline Mean personal income & -0.13297 & 0.0001 & -0.20021 & 0.0001 \\
\hline$\%$ Unemployment & 0.06932 & 0.0001 & 0.12793 & 0.0001 \\
\hline$\%$ Black & 0.03423 & 0.0575 & 0.09557 & 0.0001 \\
\hline No. of hospitals/county & -0.09438 & 0.0001 & -0.12061 & 0.0001 \\
\hline County hospital & -0.00647 & 0.7195 & -0.11305 & 0.0001 \\
\hline No. of physicians & -0.09264 & 0.0001 & -0.12322 & 0.0001 \\
\hline No. of physicians $/ 10,000$ population & -0.13898 & 0.0001 & -0.1816 & 0.0001 \\
\hline No. of ED physicians & -0.11967 & 0.0001 & -0.12595 & 0.0001 \\
\hline No. of ED physicians $/ 10,000$ population & -0.13408 & 0.0001 & -0.05706 & 0.0015 \\
\hline No. general surgeons on hospital staff & -0.07545 & 0.0001 & -0.12187 & 0.0001 \\
\hline No. Staff surgeons $/ 10,000$ population & 0.06369 & 0.0004 & -0.13465 & 0.0001 \\
\hline No. of board-certified general surgeons & -0.07596 & 0.0001 & -0.1228 & 0.0001 \\
\hline No. of board-certified general surgeons $/ 10,000$ population & 0.01431 & 0.4273 & -0.14755 & 0.0001 \\
\hline No. of all ATLS students & -0.11918 & 0.0001 & -0.11892 & 0.0001 \\
\hline No. of all ATLS students $/ 10,000$ population & -0.09398 & 0.0001 & -0.00943 & 0.6009 \\
\hline No. of ATLS general surgeons & -0.10662 & 0.0001 & -0.11276 & 0.0001 \\
\hline No. of ATLS general surgeons $/ 10,000$ population & -0.09596 & 0.0001 & -0.02704 & 0.1335 \\
\hline No. of ATLS ED MDs & -0.13691 & 0.0001 & -0.1445 & 0.0001 \\
\hline No. of ATLS ED MDs $/ 10,000$ population & -0.13308 & 0.0001 & -0.07935 & 0.0001 \\
\hline No. of AAST members & -0.06029 & 0.0008 & -0.07868 & 0.0001 \\
\hline No. of AAST members $/ 10,000$ population & -0.0433 & 0.0163 & -0.04389 & 0.0148 \\
\hline AAST member in county & -0.12156 & 0.0001 & -0.11157 & 0.0001 \\
\hline
\end{tabular}

of black residents ( $3.7 \%$ vs. 8.6\%), higher unemployment ( $7.4 \%$ vs. $6.8 \%)$, and lower average personal incomes $(\$ 11,553$ vs. $\$ 12,543)$ (Table 4). There was an average number of hospitals per county $(84 \%$ vs. $83 \%)$, fewer physicians (37 vs. 148), fewer emergency physicians (1 vs. 3), and fewer surgeons (4vs. 13).

\section{Cluster 2 (Rural Black)}

Cluster 2 consisted of 441 counties that have lower population densities ( $89 \mathrm{vs.}$. 208), a much higher percentage of black residents ( $38.6 \%$ vs. $8.6 \%$ ), higher unemployment (8.7\% vs. $6.8 \%)$, and slightly lower personal in-

Table 3. NATIONAL LOGISTIC REGRESSION

\begin{tabular}{|c|c|c|c|c|c|}
\hline $\begin{array}{c}\text { Regression Model for All } 3080 \text { U.S. } \\
\text { Counties Variable }\end{array}$ & $\begin{array}{l}\text { Parameter } \\
\text { Estimate }\end{array}$ & Standard Error & $\begin{array}{l}\text { Type II Sum } \\
\text { of Squares }\end{array}$ & $\mathbf{F}$ & Probability $>$ F \\
\hline INTERCEPT & 8.0425169 & 0.36648325 & 4017.751268 & 481.59 & 0.001 \\
\hline Log population density & -0.5034945 & 0.03995905 & 1324.54421 & 158.77 & 0.001 \\
\hline Mean personal income & -0.00006132 & 2283 & 60.17827715 & 7.21 & 0.073 \\
\hline \% Unemployment & 0.04038882 & 0.01858101 & 40.30092668 & 4.83 & 0.028 \\
\hline$\%$ Black & 0.02760658 & 387,389 & 423.6795115 & 50.78 & 0.001 \\
\hline No. of physicians $/ 10,000$ population & -0.02530082 & 926,643 & 62.19447103 & 7.45 & 0.064 \\
\hline No. of ED physicians $/ 10,000$ population & 0.00022721 & 12,107 & 29.38378451 & 3.52 & 0.0607 \\
\hline No. staff general surgeons $/ 10,000$ population & -0.09908254 & 0.05608238 & 26.0404607 & 3.12 & 0.0774 \\
\hline No. of all ATLS students $/ 10,000$ population & 0.0105663 & 387,101 & 62.15922498 & 7.45 & 0.064 \\
\hline No. of AAST members & -0.10635084 & 0.05659068 & 29.46452173 & 3.53 & 0.0603 \\
\hline
\end{tabular}


Table 4. CLUSTER \#1 1555 COUNTIES

\begin{tabular}{|c|c|c|c|c|c|}
\hline Variable & Mean & SD & Sum & Minimum & Maximum \\
\hline All deaths & 341.85 & 390.44 & 531,572 & 7 & 8392 \\
\hline Total trauma deaths & 20.36 & 28.05 & 31,662 & 0 & 674 \\
\hline All deaths $/ 10,000$ population & 99.74 & 23.15 & 155,099 & 32.16 & 197.06 \\
\hline Trauma deaths $/ 10,000$ population & 5.73 & 2.42 & 8903.86 & 0 & 22.22 \\
\hline County population & 37,915 & 53,741 & $58,958,600$ & 1800 & $1,292,500$ \\
\hline Population density & 56.12 & 49.78 & 87,265 & 3.79 & 618.06 \\
\hline Log population density & 3.74 & 0.78 & 5811.31 & 1.33 & 6.43 \\
\hline Mean personal income & 11,553 & 1852.99 & $17,964,670$ & 0 & 15,773 \\
\hline$\%$ Unemployment & 7.41 & 3.29 & 11,527 & 1.7 & 33.3 \\
\hline$\%$ Black & 3.08 & 4.88 & 4795.1 & 0 & 21.8 \\
\hline No. of hospitals/county & 1.35 & 1.24 & 2105 & 0 & 22 \\
\hline County hospital & 0.84 & 0.37 & 1304 & 0 & 1 \\
\hline No. of physicians & 37.84 & 87.35 & 58,841 & 0 & 2066 \\
\hline No. of physicians $/ 10,000$ population & 7.37 & 5.16 & 11,468 & 0 & 57.57 \\
\hline No. of ED physicians & 0.86 & 2.42 & 1334 & 0 & 39 \\
\hline No. of ED physicians $/ 10,000$ population & 134.74 & 344.87 & 209,516 & 0 & 3763.44 \\
\hline No. general surgeons on hospital staff & 3.82 & 8.08 & 5940 & 0 & 159 \\
\hline No. staff surgeons $/ 10,000$ population & 0.83 & 0.78 & 1283.67 & 0 & 5.14 \\
\hline No. of board-certified general surgeons & 2.82 & 6.34 & 4389 & 0 & 132 \\
\hline No. of board-certified general surgeons $/ 10,000$ population & 0.58 & 0.64 & 897.48 & 0 & 4 \\
\hline No. of all ATLS students & 3.22 & 10.17 & 5010 & 0 & 203 \\
\hline No. of all ATLS students $/ 10,000$ population & 6.24 & 10.25 & 9698.8 & 0 & 145.3 \\
\hline No. of ATLS general surgeons & 0.33 & 1.05 & 511 & 0 & 13 \\
\hline No. of ATLS general surgeons $/ 10,000$ population & 0.64 & 1.8 & 989.87 & 0 & 20 \\
\hline No. of ATLS ED MDs & 0.64 & 1.55 & 999 & 0 & 20 \\
\hline No. of ATLS ED MDs $/ 10,000$ population & 1.24 & 2.71 & 1934.89 & 0 & 26.32 \\
\hline No. of AAST members & 0.01 & 0.12 & 15 & 0 & 3 \\
\hline No. of AAST members $/ 10,000$ population & 0.1 & 1.41 & 155.97 & 0 & 37.31 \\
\hline AAST member in county & 0.01 & 0.09 & 12 & 0 & 1 \\
\hline
\end{tabular}

comes $(\$ 10,384$ vs. $\$ 12,543)$ (Table 5). These rural black counties have fewer medical resources: fewer hospitals ( $78 \%$ vs. 83\%), fewer physicians per county (55 vs. 148), fewer emergency physicians ( $1 v s .3$ ), and fewer surgeons (6vs. 13).

\section{Cluster 3 (Rural White)}

Cluster 3 was composed of 599 counties that have very low population densities (6vs. 208), a much lower percentage of black residents $(0.6 v s$. 8.6), lower unemployment $(5.6 \%$ vs. $6.8 \%)$, and slightly higher personal incomes $(\$ 13,610 v s . \$ 12,543)$ (Table 6). These very rural white counties have fewer medical resources: fewer hospitals $(73 \%$ vs. $83 \%)$, fewer county physicians ( $8 v s .148)$, fewer emergency physicians $(<1$ vs. 3$)$, and fewer surgeons ( $1 v s .13)$.

\section{Cluster 4 (Urban)}

Cluster 4 was made up of 485 counties that have a very high population density (1,056 vs. 208), an average percentage of black citizens ( $8.6 \%$ vs. $8.6 \%)$, lower unemployment (4.7\% vs. $6.8 \%)$, and higher personal incomes
(\$16,364 vs. \$12,543) (Table 7). These 485 counties ( $16 \%$ of the 3,080 counties) contain $67 \%$ of the nation's population. These urban and relatively rich counties have greater medical resources: more hospitals ( $95 \%$ vs. $83 \%$ ), more county physicians (759 vs. 148), more emergency physicians (14 vs. 3), and more surgeons (61 vs. 13).

\section{Total and Trauma Death Rates}

Review of the tables shows that the four groups have different total and different trauma death rates consistent with the demonstrated association of demographic factors and death rates $(5.73 \pm 2.42,6.69 \pm 2.67,6.50 \pm$ $4.86,4.20 \pm 1.22$ per-capita trauma death rates and $99.74 \pm 23.15,101.99 \pm 20.89,104.79 \pm 36.44,81.51$ \pm 21.71 for overall per-capita death rates for clusters 1 through 4 , respectively).

\section{Multivariate Analyses of the Four County Groups}

\section{Multivariate Analysis of Cluster 1 (Average Rural)}

Cluster 1 was composed of counties that were generally more rural than the overall group (Table 8). Again 
Table 5. CLUSTER \#2 441 COUNTIES

\begin{tabular}{|c|c|c|c|c|c|}
\hline Variable & Mean & SD & Sum & Minimum & Maximum \\
\hline All deaths & 352.66 & 629.19 & 155,521 & 22 & 9662 \\
\hline Total trauma deaths & 20.64 & 24.33 & 9102 & 0 & 250 \\
\hline All deaths $/ 10,000$ population & 101.99 & 20.89 & 44,977 & 12.15 & 172.73 \\
\hline Trauma deaths $/ 10,000$ population & 6.69 & 2.67 & 2948.93 & 0 & 20.75 \\
\hline County population & 37,072 & 60,282 & $16,348,700$ & 2000 & 751,400 \\
\hline Population density & 89.62 & 467.5 & 39,524 & 5.42 & 9392.5 \\
\hline Log population density & 3.8 & 0.83 & 1676.88 & 1.69 & 9.15 \\
\hline Mean personal income & 10,384 & 1637.57 & $4,579,543$ & 6617 & 15,346 \\
\hline$\%$ Unemployment & 8.2 & 3.62 & 3615.1 & 2.8 & 25.5 \\
\hline \% Black & 38.59 & 12.97 & 17,017 & 18.6 & 84.2 \\
\hline No. of hospitals/county & 1.24 & 1.57 & 547 & 0 & 17 \\
\hline County hospital & 0.78 & 0.41 & 344 & 0 & 1 \\
\hline No. of physicians & 54.85 & 251.73 & 24,189 & 0 & 4230 \\
\hline No. of physicians $/ 10,000$ population & 7.03 & 6.41 & 3101.94 & 0 & 56.29 \\
\hline No. of ED physicians & 0.94 & 4.41 & 414 & 0 & 71 \\
\hline No. of ED physicians $/ 10,000$ population & 82.56 & 218.54 & 36,409 & 0 & 1234.57 \\
\hline No. general surgeons on hospital staff & 5.89 & 30.51 & 2596 & 0 & 552 \\
\hline No. staff surgeons $/ 10,000$ population & 0.73 & 0.92 & 320.23 & 0 & 7.35 \\
\hline No. of board-certified general surgeons & 4.39 & 23.58 & 1936 & 0 & 424 \\
\hline No. of board-certified general surgeons $/ 10,000$ population & 0.49 & 0.73 & 215.28 & 0 & 5.81 \\
\hline No. of all ATLS students & 4.29 & 18.22 & 1893 & 0 & 218 \\
\hline No. of all ATLS students $/ 10,000$ population & 5.98 & 13.74 & 2637.73 & 0 & 213.73 \\
\hline No. of ATLS general surgeons & 0.32 & 1.53 & 143 & 0 & 19 \\
\hline No. of ATLS general surgeons $/ 10,000$ population & 0.47 & 1.68 & 209.15 & 0 & 15.69 \\
\hline No. of ATLS ED MDs & 0.42 & 1.53 & 186 & 0 & 18 \\
\hline No. of ATLS ED MDs $/ 10,000$ population & 0.7 & 2.03 & 307.99 & 0 & 17.65 \\
\hline No. of AAST members & 0.06 & 0.44 & 26 & 0 & 5 \\
\hline No. of AAST members $/ 10,000$ population & 0.26 & 1.83 & 114.31 & 0 & 20.08 \\
\hline AAST member in county & 0.02 & 0.15 & 10 & 0 & 1 \\
\hline
\end{tabular}

in this subgroup the first four variables selected for the model were demographic measures (log of population density, population density, unemployment, and racial distribution). After this, several measures of medical manpower resources were selected as predictive of county trauma death rates, including several measures of ATLS training of physicians. Overall, however, the regression coefficient was 0.109 , indicating that a relatively low proportion $(10 \%)$ of the outcome can be explained by this model.

\section{Multivariate Analysis of Cluster 2 (Rural Black)}

Cluster 2 was made of rural counties that have a high percentage of black residents (Table 9). These rural black counties also have fewer medical resources. The regression model for this county group selected the same four demographic variables as the most important predictors of outcome. After the demographic factors, medical resource measures, including the number of hospitals in the county, improved the predictive power of the model. The regression coefficient was 0.14 .

\section{Multivariate Analysis of Cluster 3 (Rural White)}

Cluster 3 was composed of counties that were very rural and almost all white (Table 10). These counties have few medical resources. The multivariate regression model did poorly in explaining the variation in deaths in these counties, with regression coefficient of only 0.048 . The predictive factors selected were similar to the other regression models. With such a low predictive power, other unidentified factors must affect outcome.

\section{Multivariate Analysis of Cluster 4 (Urban)}

Cluster 4 was composed of the wealthiest and most urban counties in the series (Table 11). These counties have greater medical resources in all areas measured. The regression model in this subgroup was the best of any stud- 
Table 6. CLUSTER \#3 599 COUNTIES

\begin{tabular}{|c|c|c|c|c|c|}
\hline Variable & Mean & SD & Sum & Minimum & Maximum \\
\hline All deaths & 87.25 & 122.24 & 52,260 & 0 & 2090 \\
\hline Total trauma deaths & 5.46 & 7.51 & 3271 & 0 & 79 \\
\hline MVACC86 & 2.78 & 5.59 & 1668 & 0 & 102 \\
\hline All deaths $/ 10,000$ population & 104.79 & 36.44 & 62,767 & 0 & 222.22 \\
\hline Trauma deaths $/ 10,000$ population & 6.5 & 4.86 & 3890.53 & 0 & 40 \\
\hline MVAPC & 3.03 & 3.14 & 1817.46 & 0 & 25 \\
\hline County population & 9472.95 & 23,618 & $5,674,300$ & 100 & 524,000 \\
\hline Population density & 5.91 & 4.83 & 3540.22 & 0.15 & 29.34 \\
\hline Log population density & 1.42 & 0.91 & 852.47 & -1.9 & 3.38 \\
\hline Mean personal income & 13,610 & 2911.03 & $8,152,284$ & 0 & 29,767 \\
\hline$\%$ Unemployment & 5.59 & 3.04 & 3347.6 & 0 & 33.5 \\
\hline$\%$ Black & 0.56 & 1.48 & 333.1 & 0 & 10.8 \\
\hline No. of hospitals/county & 0.94 & 1.18 & 566 & 0 & 24 \\
\hline County hospital & 0.73 & 0.45 & 436 & 0 & 1 \\
\hline No. of physicians & 7.89 & 29.25 & 4729 & 0 & 638 \\
\hline No. of physicians $/ 10,000$ population & 5.91 & 4.68 & 3542.11 & 0 & 39.39 \\
\hline No. of ED physicians & 0.13 & 1.13 & 78 & 0 & 19 \\
\hline No. of ED physicians $/ 10,000$ population & 58.09 & 755.85 & 34,794 & 0 & 17,895 \\
\hline No. general surgeons on hospital staff & 0.89 & 3.52 & 531 & 0 & 80 \\
\hline No. staff surgeons $/ 10,000$ population & 0.77 & 1.54 & 463.04 & 0 & 14.29 \\
\hline No. of board-certified general surgeons & 0.59 & 2.1 & 352 & 0 & 44 \\
\hline No. of board-certified general surgeons $/ 10,000$ population & 0.46 & 1.08 & 276.72 & 0 & 9.52 \\
\hline No. of all ATLS students & 0.92 & 2.39 & 553 & 0 & 37 \\
\hline No. of all ATLS students $/ 10,000$ population & 8.57 & 15.38 & 5136.15 & 0 & 107.14 \\
\hline No. of ATLS general surgeons & 0.08 & 0.33 & 50 & 0 & 2 \\
\hline No. of ATLS general surgeons $/ 10,000$ population & 0.72 & 3.57 & 430.34 & 0 & 41.67 \\
\hline No. of ATLS ED MDs & 0.13 & 0.55 & 79 & 0 & 5 \\
\hline No. of ATLS ED MSs $/ 10,000$ population & 0.83 & 3.63 & 494.81 & 0 & 36.23 \\
\hline No. of AAST members & 0 & 0 & 0 & 0 & 0 \\
\hline No. of AAST members $/ 10,000$ population & 0 & 0 & 0 & 0 & 0 \\
\hline AAST member in county & 0 & 0 & 0 & 0 & 0 \\
\hline
\end{tabular}

ied, with a regression coefficient of 0.33 . As in the other models, the first four variables selected for inclusion in the model were measures of county demographics (log population density, population density, unemployment, and percentage black). After these variables, the presence of a hospital; the numbers of physicians, emergency medical physicians, and ATLS trained emergency physicians; and AAST membership contributed substantially to the predictive power of the model.

\section{DISCUSSION}

Only been in the past several years has trauma been recognized for its importance as a public health problem. Since the call to action by "Injury in America,"19 the focus in society on the problem of trauma as increased steadily, and the need to improve the prevention and treatment of injured patients was recognized. Based on several studies, often limited in scope and focusing primarily on urban areas, recommendations were made to try to reverse the detrimental effect of injury on American society.

These suggestions have run the gamut from prevention (seat belts, gun control, and smoke detectors for example) to highly technical therapeutic approaches, to interventions to decrease the late complications of injury (for example, helicopters or treating septic shock with monoclonal antibodies). No well-designed large scale study documents the costs and the expected benefits of these interventions. For many of these interventions, it is difficult to perform such studies for a variety of ethical, logistical, and financial reasons. Therefore health care planners have been forced to make decisions about the effect of health care strategies without clear data on the expected outcome of the implementation of such strategies. Despite major investments in health care resources, only limited evaluations were performed to assess the benefits of a variety of expensive and potentially risky interventions, such as aeromedical transport. A focus on evaluation of the effect of these interventions on out- 
Table 7. CLUSTER \# 4485 COUNTIES

\begin{tabular}{|c|c|c|c|c|c|}
\hline Variable & Mean & SD & Sum & Minimum & Maximum \\
\hline All deaths & 2816.51 & 4849.07 & $1,366,008$ & 33 & 62,940 \\
\hline Total trauma deaths & 133.53 & 223.49 & 64,761 & 0 & 3210 \\
\hline All deaths $/ 10,000$ population & 81.51 & 21.71 & 39,532 & 26.65 & 157.8 \\
\hline Trauma deaths $/ 10,000$ population & 4.2 & 1.22 & 2038.02 & 0 & 10.59 \\
\hline County population & 339,838 & 584,166 & $164,821,300$ & 6600 & $8,587,800$ \\
\hline Population density & 1056.84 & 4020.95 & 512,568 & 11.26 & 68,632 \\
\hline Log population density & 5.93 & 1.15 & 2877.77 & 2.42 & 11.14 \\
\hline Mean personal income & 16,364 & 3140.89 & $7,936,438$ & 12,090 & 37,844 \\
\hline \% Unemployment & 4.75 & 1.81 & 2304 & 1.4 & 14.2 \\
\hline$\%$ Black & 8.68 & 9.42 & 4207.4 & 0 & 70.2 \\
\hline No. of hospitals/county & 5.08 & 8.64 & 2463 & 0 & 135 \\
\hline County hospital & 0.95 & 0.22 & 460 & 0 & 1 \\
\hline No. of physicians & 758.7 & 1547.37 & 367,970 & 3 & 20,359 \\
\hline No. of physicians $/ 10,000$ population & 18.27 & 15.9 & 8859.62 & 0.51 & 192.73 \\
\hline No. of ED physicians & 13.75 & 25.26 & 6670 & 0 & 329 \\
\hline No. of ED physicians/10,000 population & 384.74 & 421.6 & 186,599 & 0 & 6060.61 \\
\hline No. general surgeons on hospital staff & 61.07 & 124.23 & 29,618 & 0 & 1564 \\
\hline No. staff general surgeons $/ 10,000$ population & 1.41 & 1.05 & 682.36 & 0 & 10.81 \\
\hline No. of board-certified general surgeons & 48.56 & 98.34 & 23,550 & 0 & 1186 \\
\hline No. of board-certified general surgeons/10,000 population & 1.12 & 0.87 & 543.17 & 0 & 9.25 \\
\hline No. of all ATLS students & 47.43 & 93.75 & 23,005 & 0 & 938 \\
\hline No. of all ATLS students/10,000 population & 12.94 & 30.37 & 6278.16 & 0 & 606.06 \\
\hline No. of ATLS general surgeons & 4.38 & 9.22 & 2124 & 0 & 86 \\
\hline No. of ATLS general surgeons $/ 10,000$ population & 1.1 & 1.86 & 534.23 & 0 & 22.6 \\
\hline No. of ATLSED MDs & 7.55 & 11.72 & 3663 & 0 & 123 \\
\hline No. of ATLS ED MDs/10,000 population & 2.27 & 2.26 & 1100.65 & 0 & 25.64 \\
\hline No. of AAST members & 0.86 & 2.42 & 416 & 0 & 21 \\
\hline No. of AAST members $/ 10,000$ population & 1.88 & 7.81 & 911.55 & 0 & 121.21 \\
\hline AAST members in county & 0.24 & 0.42 & 114 & 0 & 1 \\
\hline
\end{tabular}

come of injury will facilitate their selection in a costeffective manner.

A variety of factors are believed to affect the outcome of injury. These include the type of injury, the injury severity, the characteristics of the alert mechanisms in the county (emergency 911 systems, ${ }^{5}$ for example), the skill and experience of prehospital care provided, ${ }^{6}$ the use of military anti-shock trousers, the triage of patients and transport to the appropriate hospital early after injury, the immediate recognition and management of serious injury, the presence of a true trauma system, an active quality assurance and improvement program, and many other factors. One of the most important factors affecting the outcome of injury is thought to be availability of physicians skilled and experienced in the rapid assessment and treatment of injured patients. ${ }^{20-22}$ Because of the belief in the importance of physician commitment to trauma care, the ACS and the ACS Committee on Trauma dedicated a substantial effort to promoting the ATLS course. The fundamental assumption of ATLS is that a well-trained physician can have a substantial positive effect on the survival and the morbidity of the in- jured patient by intervention in care early after injury. ${ }^{23}$ Conversely it is assumed that in the absence of such skilled and available physicians, the outcome of the injured patient will be worse. To improve the available resources of physicians well trained in the immediate management of the seriously injured patient, the ACS and its Committee on Trauma spent countless volunteer hours to develop and refine the ATLS curriculum and to train students in the early management of the injured patient.

Although all of these references to the importance of the health care team and to special training and expertise in trauma seem reasonable, few data document these hypotheses and none measure the cost-benefit ratio for the members of the health care team. The following questions must be addressed: (1) What is the role of emergency medicine physicians in the care of injured patients? (2) How many emergency medicine physicians are needed? (3) How many surgeons are needed? (4) Where should they be located? (5) What level of training, interest, and commitment is needed to affect the outcome of the injured patient? (6) How important is their training in ATLS? Our study was designed to begin to 


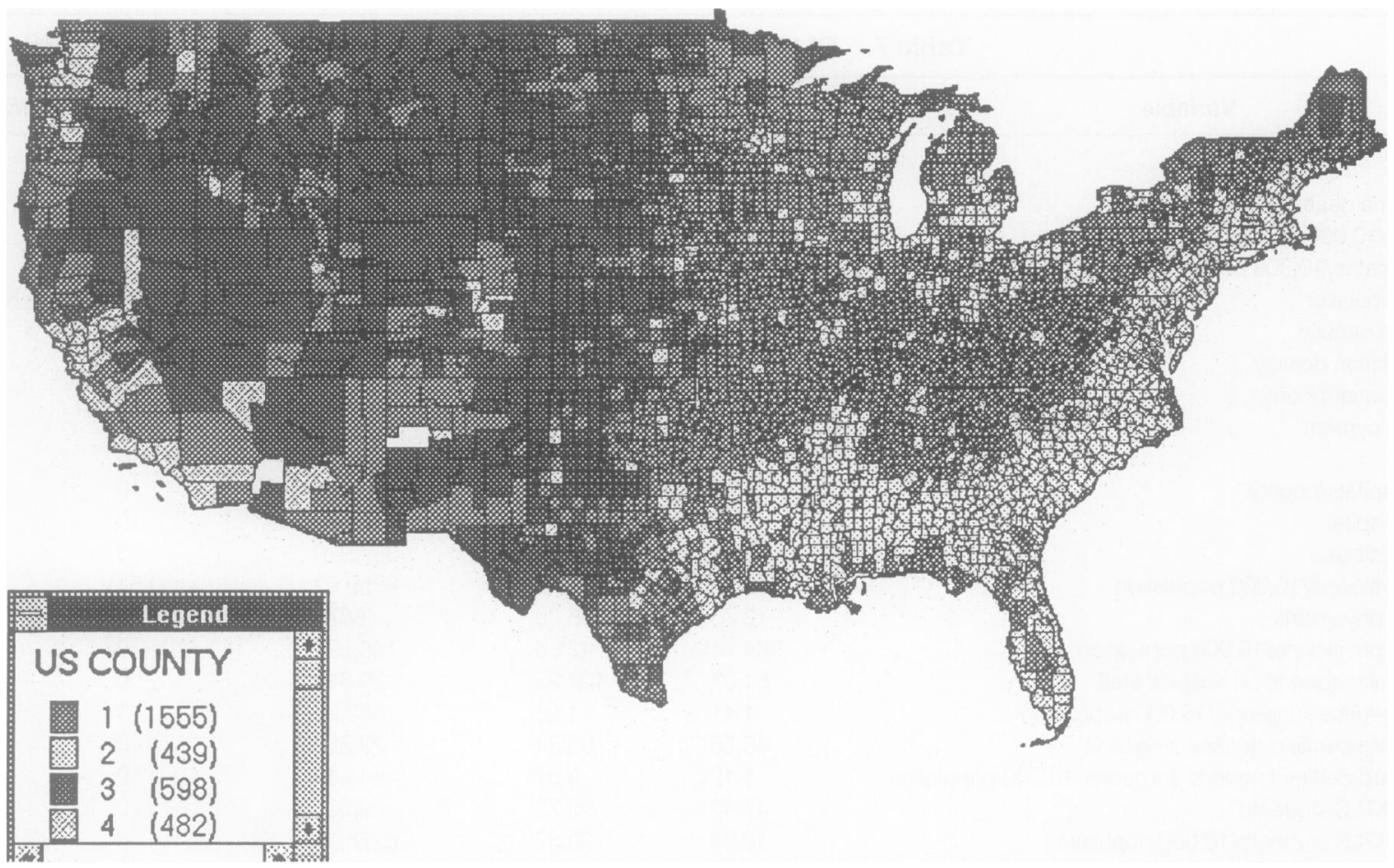

Figure 14. United States map of county clusters.

develop the tools and techniques to answer such questions.

\section{Study Findings}

Many of the findings of this study confirm those of other similar studies. ${ }^{4-9}$ The most powerful predictor of the trauma death rate in a county is the population density (or the transformed variable in the logarithm of the population density). This confirms Baker's ${ }^{4}$ work show- ing that rural American counties have substantially higher trauma death rates per capita. Of almost equal weight is the association of measures of poverty as predictors of injury death rates. Clearly the lower the county income and the higher the unemployment rate, the higher the death rate from injury. Although racial distribution was an important predictor of increased death rate, this association may not be any different from the identification of an association with poverty and trauma death rates, because blacks in America have higher rates

Table 8. CLUSTER \#1

\begin{tabular}{lccccc}
\hline \multicolumn{1}{c}{ Variable } & $\begin{array}{c}\text { Parameter } \\
\text { Estimate }\end{array}$ & $\begin{array}{c}\text { Standard } \\
\text { Error }\end{array}$ & $\begin{array}{c}\text { Type II Sum of } \\
\text { Squares }\end{array}$ & F & Probability $>$ F \\
\hline INTERCEPT & 10.03817227 & 0.43947203 & 2738.625579 & 521.73 & 0.0001 \\
Log population density & -0.63125317 & 0.08668553 & 278.3554453 & 53.03 & 0.0001 \\
Mean personal income & -0.00017124 & 0.00003391 & 133.8207871 & 25.49 & 0.0001 \\
\% Black & 0.07472689 & 0.01227908 & 194.4051661 & 37.04 & 0.0001 \\
No. of physicians/10,000 population & -0.04349594 & 0.01413512 & 49.70320071 & 9.47 & 0.0021 \\
No. of ED physicians/10,000 population & 0.0004656 & 0.0001828 & 34.05186 & 6.49 & 0.011 \\
No. of all ATLS students & -0.02111151 & 0.0097405 & 24.65824568 & 4.7 & 0.0304 \\
No. of all ATLS students/10,000 population & 0.0228814 & 0.00782031 & 44.93885782 & 8.56 & 0.0035 \\
No. of ATLS ED MDs & 0.17544438 & 0.0702308 & 32.75740471 & 6.24 & 0.0126 \\
No. of ATLS ED MDs/10,000 population & -0.10819142 & 0.03193984 & 60.22905242 & 11.47 & 0.0007 \\
& & & & & \\
R2 $=0.109$. & & & & & \\
\hline
\end{tabular}


Table 9. CLUSTER \#2

\begin{tabular}{lccccc}
\hline \multicolumn{1}{c}{ Variable } & $\begin{array}{c}\text { Parameter } \\
\text { Estimate }\end{array}$ & $\begin{array}{c}\text { Standard } \\
\text { Error }\end{array}$ & $\begin{array}{c}\text { Type II Sum } \\
\text { of Squares }\end{array}$ & F & Probability $>$ F \\
\hline INTERCEPT & 8.99720369 & 1.40325749 & 257.8093278 & 41.11 & 0.0001 \\
County population & -0.00001665 & 0.00000742 & 31.61933404 & 5.04 & 0.0252 \\
Log population density & -0.68155839 & 0.270115 & 39.92703008 & 6.37 & 0.012 \\
Mean personal income & 0.00012336 & 0.0000966 & 10.22747325 & 1.63 & 0.2023 \\
\% Unemployment & -0.10239102 & 0.03932375 & 42.51793801 & 6.78 & 0.0095 \\
\% Black & 0.0112417 & 0.00996724 & 7.97760269 & 1.27 & 0.026 \\
No. of hospitals/county & 0.35647469 & 0.17002527 & 27.56694862 & 4.4 & 0.0366 \\
No. of physicians/10,000 population & -0.07707411 & 0.03227533 & 35.76300763 & 5.7 & 0.0174 \\
No. of ED physicians & 0.09076303 & 0.07093092 & 10.26845275 & 1.64 & 0.2014 \\
No. of AAST members & 0.64515792 & 0.3809666 & 17.98336397 & 2.87 & 0.0911
\end{tabular}

$\mathrm{R} 2=0.1357$

of unemployment and lower wages, and both were identified as strong predictors of increased death rates.

\section{Study Limitations}

Despite extensive efforts to use the best available data sources and analytic techniques, this study was limited and its conclusions must be viewed as preliminary. Of primary concern is the lack of an accurate, detailed, available national data source on injury. As noted previously, this lead the ACS, under the leadership of the ACS Committee on Trauma, to make a large investment in the development of a National Trauma Registry. In the absence of such a data source, the information about the frequency and outcome of injury on a national scale is limited to the National Center for Health Statistics Death Certificate file. This data source, although valuable, has limitations for performing this kind of study.
The data provide information only on deaths from injury, and the quality of the death certificate information may vary from state to state. Because only information on trauma deaths is obtained, the overall frequency of all injuries and the severity of the injuries that lead to death are unknown. Another problem is that an unrecognized systematic bias may be present in the data base in that persons in some counties may sustain more frequent and more severe injuries, leading to higher death rates unrelated to medical interventions. In fact, other studies suggest that this is true, with more severe injuries occurring in rural counties. ${ }^{4}$ In addition, other factors, such as time to discovery, character of prehospital care, and many variables for which no information was available in this study, cannot be controlled. To control for as many of these variables as possible, we used several techniques, including multivariate analysis and evaluation of subgroups of counties separated by cluster analysis. Thus ru-

Table 10. CLUSTER \#3

\begin{tabular}{|c|c|c|c|c|c|}
\hline Variable & $\begin{array}{l}\text { Parameter } \\
\text { Estimate }\end{array}$ & $\begin{array}{c}\text { Standard } \\
\text { Error }\end{array}$ & $\begin{array}{c}\text { Type II Sum of } \\
\text { Squares }\end{array}$ & $\mathbf{F}$ & Probability $>$ F \\
\hline INTERCEPT & 6.795566 & 0.57070472 & 3233.846782 & 141.78 & 0.0001 \\
\hline Population density & 0.18536425 & 0.08684703 & 103.9042021 & 4.56 & 0.0332 \\
\hline Log population density & -1.42811307 & 0.48125999 & 200.8430272 & 8.81 & 0.0031 \\
\hline$\%$ Unemployment & 0.126347 & 0.06580551 & 84.08071857 & 3.69 & 0.0553 \\
\hline$\%$ Black & 0.29890149 & 0.13439564 & 112.8176114 & 4.95 & 0.0265 \\
\hline County hospital & -0.5693 & 0.49704432 & 29.92149063 & 1.31 & 0.2525 \\
\hline No. general surgeons on hospital staff & -0.41330938 & 0.25851465 & 58.30036944 & 2.56 & 0.1104 \\
\hline No. of board-certified general surgeons & -0.55609002 & 0.44008554 & 36.41724597 & 1.6 & 0.2069 \\
\hline No. of all ATLS students/10,000 population & 0.03125949 & 0.0134439 & 123.3117405 & 5.41 & 0.0204 \\
\hline No. of ATLS ED MDs & -0.37919551 & 0.39325999 & 21.20596009 & 0.93 & 0.3353 \\
\hline
\end{tabular}


Table 11. CLUSTER \#4

\begin{tabular}{lcccrc}
\hline \multicolumn{1}{c}{ Variable } & $\begin{array}{c}\text { Parameter } \\
\text { Estimate }\end{array}$ & $\begin{array}{c}\text { Standard } \\
\text { Error }\end{array}$ & $\begin{array}{c}\text { Type II Sum } \\
\text { of Squares }\end{array}$ & F & Probability $>$ F \\
\hline INTERCEPT & 7.38171005 & 0.3502675 & 449.0343294 & 444.13 & 0.0001 \\
Population density & 0.00002573 & 0.00001501 & 2.97192541 & 2.94 & 0.0871 \\
Log population density & -0.73148075 & 0.05680733 & 167.6340698 & 165.8 & 0.0001 \\
\% Unemployment & 0.07319839 & 0.02642184 & 7.75964976 & 7.67 & 0.0058 \\
\% Black & 0.03440776 & 0.00541627 & 40.80161609 & 40.36 & 0.0001 \\
County hospital & 0.52323164 & 0.2216488 & 5.6340734 & 5.57 & 0.0186 \\
No. of physicians/10,000 population & -0.01626551 & 0.00453761 & 12.99111472 & 12.85 & 0.0004 \\
No. of ED physicians/10,000 population & -0.00023967 & 0.00013463 & 3.20442141 & 3.17 & 0.0757 \\
No. of ATLS ED MDs & -0.0188043 & 0.00545274 & 12.02401601 & 11.89 & 0.0006 \\
No. of AAST members/10,000 population & -0.02867124 & 0.00809938 & 12.6693687 & 12.53 & 0.0004 \\
& & & & & \\
R2 = 0.33. & & & & &
\end{tabular}

ral counties were analyzed separately from urban counties.

In addition to limitations with the data available for the dependent variable (county per-capita trauma death rate), the data sets we used for the independent variables also had important limitations. The ATLS course has been a point of major commitment for the care of injured patients by the ACS. Yet few data document its value. ${ }^{23}$ In this study, the total number of ATLS-trained physicians could not be identified. Only a sample of all ATLS physicians were available in the data base at the ACS. This limits any statements that can be made from these analyses. If all ATLS data were available, a different relation between these measures and trauma death rates might be identified.

Use of AAST membership as an independent variable might seem limited because of its small size. The AAST has approximately 900 members, and these are largely concentrated in urban areas, which explains their effect only in the urban cluster analysis. Rather than simply an analysis of the trauma care provided by AAST members, the statistically significant association probably reflects the presence of a group of health professionals committed to care of the injured.

The study appears to support continued commitment of resources to the care of trauma patients. Maintenance of interested and well-trained physicians and surgeons for trauma care is very important. Recent work raises concerns about maintaining such manpower resources $^{21,22}$

\section{CONCLUSIONS}

The primary goal of this study was to assess the association between measures of medical manpower and the trauma death rate in the U.S. counties. Using a variety of techniques, we found that numbers of physicians, surgeons, and emergency physicians, and ATLS training and AAST membership were associated with lower rates of trauma death. This is true in the bivariate analyses, the multivariate analyses of the entire nation, and in the analysis of the counties clustered by demographic factors.

There seems to be a consistent association between various measures of medical manpower and trauma death rates. But because of the multiple internal correlations, incompletely controlled for effects of demographic factors, and the limitations of the data themselves, no conclusions about a causative effect between these factors and trauma deaths can be made.

On the other hand, these findings are consistent with the hypothesis that manpower resources are important in affecting the outcome of injured patients, and this is the first study of its type to try to quantify that association. It raises the issue of the need for accurate population-based detailed data on injury and on the resources used to care for the injured patient. In fact, this study stands as a cogent argument for the development and support of a national data source on injury as envisioned by the ACS.

This study confirms previous work showing the relations among poverty and rurality and increased county trauma death rates. It is the first study to show that counties with more physicians per capita and with more surgeons who are committed to trauma care (AAST membership) or who receive increased training (ATLS) in trauma care have lower per-capita trauma death rates. These findings suggest that increased interest and training in trauma care, along with more effective allocation of manpower and resources used to treat injury can decrease the devastating effect of trauma in the United States. 


\section{References}

1. U.S. Bureau of the Census. Statistical Abstract of the United States: 1993. 113th ed. Washington, DC, 1993.

2. Rutledge R, Lalor A, Oller D, et al. The cost of not wearing seat belts. A comparison of outcome in 3396 patients. Ann Surg 1993; 217:122-127.

3. West JG, Trunkey DD, Lim RC. Systems of trauma care: a study of two counties. Arch Surg 1979; 114:455-460.

4. Baker SP, Whitfield RA, O'Neill B. Geographic variations in mortality from motor vehicle crashes. N Engl J Med 1987; 316:13841387.

5. Patsey T, Messick J, Rutledge R, et al. A population-based, multivariate analysis of the association between 911 access and percapita county trauma death rates. Ann Emerg Med 1992; 21:11731178.

6. Messick WJ, Rutledge R, Meyer AA. The association of advanced life support training and decreased per capita trauma death rates: An analysis of 12,417 trauma deaths. J Trauma 1992; 33:850-855.

7. Rutledge R, Messick J, Baker CC, et al. Multivariate populationbased analysis of the association of county trauma centers with per capita county trauma death rates. J Trauma 1992; 33:29-37.

8. Oller DW, Rutledge R, Clancy $T$, et al. Vascular injuries in a rural state: a review of 978 patients from a state trauma registry. J Trauma 1992; 32:740-745.

9. Rutledge R, Messick WJ. The association of trauma death and alcohol use in a rural state. J Trauma 1992; 33:737-742

10. Anderberg MR. On some significance tests in cluster analysis. In Cluster Analysis for Applications. New York: Academic Press, 1985.

11. Calinski T, Harabasz J. A dendrite method for cluster analysis. Communications in Statistics 1974; 3:1-27.

12. Cooper MC, Milligan GW. The effect of error on determining the number of clusters. Proceedings of the International Workshop on Data Analysis, Decision Support and Expert Knowledge Representation in Marketing and Related Areas of Research. New York: John Wiley, 1988.

13. Hartigan JA. Clustering Algorithms. New York: John Wiley \& Sons, 1975.

14. MacQueen JB. Some methods for classification and analysis of multivariate observations. Proceedings of the Fifth Berkeley Symposium on Mathematical Statistics and Probability 1967; 1:281297.

15. McLachlan GJ, Basford KE. Mixture Models. New York: Marcel Dekker, 1988.

16. Mezzich JE, Solomon H. Taxonomy and Behavioral Science. New York: Academic Press, 1980.

17. Pollard D. Strong consistency of K-means clustering. Ann Stat 1981; 9:135-140.

18. Sarle WS. SAS Technical Report A-108, The Cubic Clustering Criterion. Cary, NC: SAS Institute, 1983.

19. Institute on Medicine. Injury in America: A Continuing Health Problem. Washington, DC: National Academy Press, 1985.

20. Committee on Trauma of the American College of Surgeons. Resources for the Optimal Care of the Injured Patient. American College of Surgeons. Chicago, IL, 1990.

21. Sheldon GF. Trauma manpower in the decade of aftershock. Bull Am Coll Surg 1992; 77:6-12.

22. Richardson JD, Miller FB, Polk HC Jr. Can we improve the surgical manpower for providing trauma care? A model for success [Editorial]. J Trauma 1993; 34:773-774.

23. Ali J, Howard M. The Advanced Trauma Life Support Program in Manitoba: a 5-year review. Can J Surg 1993; 36:181-183.

\section{Discussion}

DR. C. R. F. BAKER (Lubbock, Texas): Dr. Meyer and his co-authors are to be commended on their excellent paper. They have demonstrated a clear association between surgical training and interest with a decrease in deaths from trauma. The Texas Department of Health Statistics support the authors' conclusions regarding rural trauma death rates. Lubbock County has a high number of injuries yet a low mortality rate. And here we have the lowest mortality rate, presumably because of some of the factors Dr. Meyer's is talking about. These West Texas counties are perhaps 40 miles wide and 30 miles tall, and in our region, because of these geographic distances, the county there in the western part of our region which is roughly a 100 miles away has a very high mortality rate. This distance is going to translate into increased mortality. Time is mortality in the severely injured patient. The authors have focused on surgical training to improve outcomes, and implementation of the other elements of a trauma system should further decrease mortality.

DR. J. DA VID RICHARDSON (Louisville, Kentucky): It's an interesting study that examines the effects of various models in attempting to explain differences found between county death rates due to trauma in 3080 counties in the United States. And in that regard, it certainly is a monumental effort. A number of computer-based statistical tests were used, and I certainly would be intellectually dishonest if I imply in any way that I had any real expertise in some of this computer modeling. I think the paper is fairly complicated in that regard. If one asks me my opinion about death rates due to trauma as based on population, I would have suspected that it would have probably balanced out and that urban death rates due to increased violence might have counterbalanced the effects seen from blunt trauma and non-access to care. In point of fact, these data clearly show that that's not the case. And not only are trauma death rates higher, but death rates from all causes are much higher in all the rural areas. The death rates from trauma in this paper reiterate previous work from North Carolina and also underscore some of the studies that we've done in Kentucky which show that patients injured in rural counties have a higher death rate than those in urban counties. We've also done some work with Dr. Gene Shively, one of the members of this organization, in showing that by regionalizing care with a wheeland-spoke model, if you will, we think we've been able to significantly decrease at least trauma death rate in Kentucky. I believe the authors' conclusions are probably correct, but I'm not real sure that the study exactly proves this. I have several concerns about methodology. First, I'm very concerned about the reliability of the death rates by county. In Kentucky, for example, the death certificates usually comes from the funeral home. We do not have a true ME system. Our coroners are almost always funeral directors in virtually every county. I wonder, for example, if a person who lives in rural Henry County in Kentucky, is on his way to Louisville to work, is injured in suburban Oldham County, gets transported to Jefferson County, to our hospital, and subsequently dies there, who gets the blame or the credit, depending on your point of 